\title{
La participación de José de la Riva Agüero y Sánchez Boquete en el proceso de la independencia del Perú vista a través de sus memorias
}

\section{The involvement of José de la Riva Agüero y Sánchez Boquete in the independence process of Peru, as seen through his memoirs}

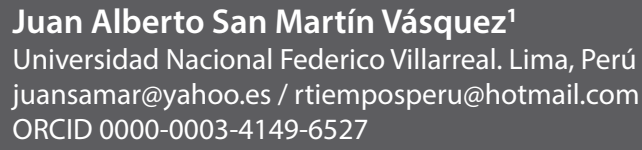

Citar como: San Martín, J. (2020). La participación de José de la Riva Agüero y Sánchez Boquete en el proceso de la independencia del Perú vista a través de sus memorias. Desde el Sur, 12(1), pp. 37-55.

\section{RESUMEN}

En sus memorias, escritas cuando ya estaba fuera del Perú y retirado de la actividad pública, José de la Riva Agüero y Sánchez Boquete utiliza el seudónimo de Pruvonena y analiza su participación política en el proceso de la independencia peruana, en la que asume una postura de enfrentamiento contra el Congreso, luego de ser reconocido como presidente del Perú por el Poder Legislativo. Acusó a sus miembros de demagogos y de otorgar el poder absoluto a Simón Bolívar y las tropas de la Gran Colombia para acabar con las fuerzas realistas, lo cual consideró una afrenta hacia el ejército nacional, pues ello implicaba la postergación de la oficialidad peruana. La actitud temperamental de Riva Agüero, reflejada en su actuación políti$\mathrm{ca}$, en la que cometió diversos errores que lo llevaron a su destitución como presidente, y justificada en sus memorias, permiten comprender la anarquía y la debilidad del naciente Estado peruano en los primeros años de nuestra vida republicana.

1 Licenciado en Historia, miembro de número del Centro de Estudios Hitórico Militares del Perú y director de la revista de historia y cultura Tiempos. 


\section{PALABRAS CLAVE}

José de la Riva Agüero, Pruvonena, José de San Martín, Simón Bolívar, marqués de Torre Tagle

\section{ABSTRACT}

In his memoirs, written when he had left Peru and had retired from public service, José de la Riva Agüero y Sánchez Boquete, using the pseudonym "Pruvonena", analyzed his political involvement in the process of Peruvian independence, in which he actively opposed Congress, accusing its members of being demagogues and of handing absolute power to Simón Bolívar and to the troops of Gran Colombia in the struggle to defeat Spanish forces, which he considered an affront to the national army, since it entailed the subordination of Peruvian officers. The attitude of Riva Agüero, as reflected in his political activities, in which he made several errors that resulted in his removal as president, is defended in his memoirs, which offer an insight into the weakened and anarchic condition of the nascent Peruvian state during the early years of the republic.

\section{KEYWORDS}

Riva Agüero, Pruvonena, San Martín, Simón Bolívar, Torre Tagle

\section{Introducción}

José de la Riva Agüero y Sánchez Boquete, primer presidente de la República, fue un personaje central en el proceso de la independencia peruana. Sus ambiciones políticas y su acendrado nacionalismo lo llevaron a cometer errores políticos en su afán de conseguir la libertad del Perú del yugo español y en su propósito de deshacerse de Bolívar y las tropas colombianas, a quienes consideraba un peligro para la estabilidad política del país. En sus memorias, escritas ya en su madurez y lejos del Perú, Riva Agüero toma el nombre de Pruvonena para alejarse del protagonismo político y escribe en tercera persona. Se trata a sí mismo como un actor político más en el enmarañado escenario de la política peruana de comienzos de la República.

Hombre apasionado y con aspiraciones políticas por su ascendencia noble, Riva Agüero escribe en sus memorias con cierta amargura sobre las fatalidades del Perú y recuerda haber sido postergado por el Libertador San Martín a un cargo burocrático sin importancia, cuando él ansiaba 
ser el líder que sacaría a los españoles del Perú. Luego, en 1823, al ser impuesto por el ejército como primer presidente peruano, fue destituido a los pocos meses por los miembros del Primer Congreso Constituyente, a quienes Riva Agüero consideraba los culpables de la anarquía en el país por practicar la demagogia y otorgar el poder absoluto a Simón Bolívar, en desmedro de los oficiales peruanos, que según él podían liquidar a los peninsulares.

Al entrar en negociaciones con el virrey La Serna, para expulsar a Simón Bolívar y al ejército colombiano, el presidente Riva Agüero cometió un grave error, pues puso en peligro el logro de la independencia del Perú, por la que tantos peruanos habían luchado. En razón de ello, fue destituido de la Presidencia por orden del Congreso y apresado por Bolívar. De esta manera, el controvertido presidente Riva Agüero fue conducido al exilio en Europa, y así se puso fin a una primera etapa de su vida signada por las conspiraciones y las ambiciones personales que le granjearon enemistades profundas. Por ese motivo, un alto porcentaje de la historiografía peruana le desconoce sus méritos y aportes en el logro de la independencia del Perú.

\section{Capítulo 1}

\section{Perfil biográfico de Pruvonena, su gobierno y su visión del Perú (1823)}

El prócer de la independencia peruana y gran mariscal José Mariano de la Riva Agüero y Sánchez Boquete nació en Lima el 3 de mayo de 1783, hijo de los nobles españoles José de la Riva Agüero y Basso de la Rovere, caballero de la Orden de Carlos III, y María Josefa Sánchez Boquete y Román de Aulestia, heredera del marqués de Montealegre de Aulestia. Siendo muy joven, fue enviado a España, en donde concluyó su educación y contó con la protección de su tío, el marino andaluz Bertodano. A pesar de que sus padres deseaban que siguiera la tradición familiar de la profesión de las armas, Riva Agüero, llevado por su interés de conocer la actividad política y social de otros países europeos, decidió interrumpir su cómoda vida en la sociedad española y dejó

su carrera militar y después sus estudios de leyes e hizo un largo viaje de paseo a Francia. Regresó a Madrid en vísperas de la guerra de la Independencia. Al principio de ella estuvo en varios encuentros en Guipúzcoa y Burgos, y se reunió en la división de Echevarría en Córdoba, pocos días antes del combate de Alcolea. Parece que ya por entonces se había afiliado a una de las logias que trabajaban por la emancipación de América (Riva-Agüero, 1971, p. 166).

De esta manera, se puede apreciar que el viaje de Riva Agüero tenía una finalidad política, que lo llevó a interesarse por la suerte de la tierra 
que lo vio nacer. En su mente empezó a concebir la idea de luchar por la liberación de su patria. En 1809 viajó a Buenos Aires. Al saber de su llegada al Río de la Plata, las autoridades peninsulares trataron de prenderlo para regresarlo a España, pero Riva Agüero escapó de la vigilancia de la autoridad colonial y llegó al Perú. Con la ayuda de su cuñado, el intendente de Lima Juan María Gálvez, consiguió un empleo en el Tribunal Mayor de Cuentas. Desde entonces Riva Agüero tuvo contacto con diferentes personas que tenían en mente lograr la independencia y liberarse de la tutela española. Además, el futuro primer presidente del Perú enviaba información al gobierno de Chile de O'Higgins sobre las actividades del gobierno realista y utilizaba diferentes seudónimos para no ser descubierto. Por este motivo, fue vigilado constantemente por los enviados del virrey Abascal. De esa forma colaboró con el plan de campaña de San Martín, que se hallaba en Chile preparando la expedición libertadora al Perú. Anota José de la Riva-Agüero y Osma sobre su bisabuelo que

Ya por esa época era agente secreto en el Perú de las juntas separatistas de Buenos Aires y Chile, y dirigía la Logia de Lima, que funcionaba en su propia casa y a veces en la del conde de la Vega del Ren, el cual era uno de sus más principales auxiliares [...] Se le halló complicado en la conjuración de Quirós y Pardo de Zela, en la de Gómez y en la de 1819; estuvo preso en 1820, y cuando desembarcó San Martín organizó el pronunciamiento del batallón Numancia, y las guerrillas de las inmediaciones de la capital (Riva-Agüero, 1971, p. 167).

Como activo conspirador, Riva Agüero se propuso darle fin al dominio peninsular en el Perú y, para ello, utilizó sus recursos, desde su posición social y económica, para que algunos oficiales del ejército español desertaran a favor del ejército patriota de San Martín. Una vez que el Libertador llegó a Huaura, Riva Agüero fue a darle el encuentro y se unió a sus filas. Ya durante el protectorado de San Martín, Riva Agüero recibió el cargo de presidente del departamento de Lima, un puesto político que equivale al de gobernador o prefecto en el presente, pero luego fue postergado por los lugartenientes del Protector. Al observar que el ministro Bernardo de Monteagudo dictaba órdenes de secuestro de bienes contra los españoles y hasta el destierro de ellos hacia España, Riva Agüero optó por apoyar el complot para sacar del poder al hombre de confianza de San Martín, pues siempre su posición política fue la de combatir cualquier tipo de autoritarismo. Así, en un documento titulado «Lima justificada en el levantamiento patriótico del 25 de julio de 1822», manifiesta sobre el Protector del Perú que:

Su ambición era ilimitada; se había hecho el árbitro aun del gobierno mismo. Tenía el descaro de citar órdenes y decretos a su nombre, 
contrariando el Estatuto provisorio; ponía en otros el nombre de la suprema autoridad, con el fin, sin duda, de hacerla odiosa. Una conducta semejante en el tiempo crítico de estar el ejército enemigo a 40 leguas de la capital y de que el gobierno aún no estaba constituido, ¿no prueba que sus miras eran minar los cimientos del Estado? (Rávago, 1999, p. 508).

Riva Agüero tomó distancia del Libertador San Martín quizá por no ser tomado en cuenta como fundador de la Orden del Sol y por algunas inconductas sociales que observó en el Protector, que a su juicio lo inhabilitaban para ejercer el gobierno, tema que trataremos más adelante. Luego de la salida de San Martín y el fracaso de la Junta Gubernativa nombrada por el Congreso, que no pudo aplicar un plan de acción eficaz contra el ejército del virrey La Serna establecido en el interior del país, Riva Agüero fue impuesto por el ejército patriota como primer presidente del Perú a raíz del motín de Balconcillo. El Congreso de la República, mal de su agrado, tuvo que reconocerlo como nuevo jefe de Estado. El presidente se dio a la tarea de reordenar las finanzas y sacar máximo provecho del ingreso económico por las rentas y los impuestos fiscales para armar y conformar un ejército fuerte que combatiera a las fuerzas del virrey La Serna en el sur. Asimismo, Riva Agüero pidió ayuda a Chile a través de uno de sus ministros y solicitó a Simón Bolívar y al ejército colombiano que vinieran al Perú para juntos acabar con las tropas de La Serna, pues la presencia del ejército español en territorio peruano era un peligro para la libertad de América. La visión del presidente era liberar a la región y el eje ColombiaPerú-Chile era vital para conseguir el triunfo final sobre los peninsulares. Así, Riva Agüero demostró su capacidad de estadista y su posición nacionalista para lograr la independencia y

su preocupación constante e infatigable actividad por realizarla en apretada cooperación con el propio Bolívar, para quien en uno de los párrafos de su carta de 9 de abril: «Inmortalidad al presidente Bolívar, que a los tres días de la llegada de nuestro enviado, hizo dar a la vela a su división». Coincidiendo con la gestión encargada a Larrea y Loredo, había salido de Chile el ministro plenipotenciario Joaquín Campino para ofrecer al Perú los recursos que su país había acordado proporcionarle y a cuya suerte final estaba indisolublemente unida la República chilena (Rávago, 1999, p. 100).

Por otro lado, el presidente Riva Agüero había obtenido la aceptación del préstamo solicitado en Londres. La transferencia de dinero fue entregada a su gobierno por partes por el de Chile, para financiar la campaña militar contra el ejército de La Serna. En este objetivo se abocó a organizar una expedición a Intermedios, que encomendó al general Santa Cruz, 
quien partió al sur con 6000 hombres para enfrentar a los realistas. A pesar de que el presidente coordinó con los generales el plan de cerco a los peninsulares, la impericia y la lentitud de Santa Cruz produjeron el fracaso de la operación militar y eso permitió que el ejército español tuviera el tiempo necesario para reorganizarse en la región central. Sin embargo, el bisnieto del presidente afirma que las diferencias existentes entre las tropas de Sucre y las de Santa Cruz fueron el motivo de la debacle de las fuerzas patriotas. Así,

El ejército del Centro no abrió campaña sobre Jauja y Huancayo en combinación con el de Santa Cruz por el Sur, porque Sucre, alterando el plan de operaciones primitivo, se dirigió a la costa de Arequipa con 3000 hombres que eran la mejor de los destinados al avance sobre Jauja y el Apurímac [...] el llamado ejército del Centro o sea la división colombiana de Valdés y las restantes tropas acantonadas en el Callao y Lima, quedó muy enflaquecido, minado por las eternas e inevitables desavenencias entre los jefes colombianos de un lado, y de otro los argentinos y peruanos, y totalmente incapaz de atreverse por sí solo a la ocupación de Jauja y Huamanga. Necesitaba para esto el concurso del ejército del Norte, bien haciéndolo transportar a Lima, bien haciéndolo avanzar por Huánuco y Pasco. Pero este ejército, que fue el núcleo de los cuerpos peruanos que más tarde cooperaron a las victorias de Junín y Ayacucho, no existía entonces (julio de 1823) (Riva-Agüero, 2010, p. 501).

Se puede apreciar que el presidente Riva Agüero, que ejercía el liderazgo de un militar con visión geográfica y conocedor del carácter de los peruanos, puso su empeño en combatir al enemigo español aun cuando ya un mes antes el Congreso le había quitado las prerrogativas de jefe del Poder Ejecutivo para preparar la llegada de Bolívar y entregarle todo el poder político del país. En efecto, en junio de 1823, el Congreso le otorgó a Sucre el mando militar del ejército unido y el 23 de ese mes decretaba la deposición de Riva Agüero al cargo de presidente para darle todo el poder al enviado de Bolívar. ¿Por qué los congresistas odiaban tanto a Riva Agüero al punto de conminarlo a renunciar a la presidencia? Es probable que muchos parlamentarios habían quedado molestos por la imposición del ejército hacia ellos, a través del motín de Balconcillo, que los obligaba a reconocer como presidente a un coronel de milicias como Riva Agüero, un hijo de nobles españoles en quien no podían confiar el mando supremo de la República para liberar al Perú del dominio hispano. Ante esta crisis política, es un hecho que hubo un acuerdo entre Sucre y Riva Agüero para que este siguiera en el ejercicio de sus funciones como presidente y se diera paso a la unidad de las fuerzas patriotas para hacer frente a un enemigo común y de esta forma: 
Sucre reconocía a Riva Agüero como presidente, quien conservaría el mando militar en todo el norte, pasando él al sur a tomar a su cargo la dirección de las fuerzas, conforme a lo dispuesto por el Comando y el Poder Ejecutivo, según lo cual los cuerpos del ejército guardarían entre sí la más estrecha armonía y el general Sucre seguiría su conducta como un simple aliado. [...] En ese estado de cosas, Riva Agüero se embarcó en la Peruviana rumbo a Huanchaco (Rávago, 1999, p. 132).

Riva Agüero tomó su posición en Trujillo acompañado de una parte del Congreso que le era hostil, pero ahí tenía la ventaja de poseer el apoyo de los oficiales del ejército peruano, como el coronel Antonio Gutiérrez de la Fuente y de varias familias que componían la aristocracia trujillana. De esta manera, el presidente decidió pasar a la ofensiva y disolvió el Congreso por decreto del 19 de julio de 1823. Luego, nombró a 10 senadores que lo acompañarían en la tarea de legislar sobre temas políticos y económicos que conllevaran a lograr la victoria final sobre el ejército realista. Varios diputados que habían sido desterrados por Riva Agüero desde Trujillo hacia el sur, en donde se encontraba el general Santa Cruz, lograron escapar y llegaron a Lima para integrarse al Congreso Constituyente. Poco después, el primer día de setiembre, llegó a Lima el Libertador Simón Bolívar. Al día siguiente, el Congreso, por decreto, le otorgó facultades de gobernante del Perú. Nombrado dictador por el Congreso, Bolívar envió comisionados a Riva Agüero para instarlo a que depusiera su actitud rebelde y reconociera el gobierno de Lima encabezado por Torre Tagle como legítimo. Sin embargo, los comisionados enviados por Riva Agüero tenían instrucciones claras y así establecieron antes sus pares enviados por el Libertador que

las fuerzas terrestres del Perú debían conservarse unidas e intactas, bajo el mando autónomo de un general peruano, con jefes garantizados contra las remociones arbitrarias; exigíase además, que en caso de hacerse necesarias legítimas subrogaciones, los nuevos jefes fueran peruanos, que por ningún motivo se disolviera un cuerpo del Perú, y que en caso de menoscabarse sus efectivos se reemplazaran las bajas. Nada descuidaba, en fin, el partido de Riva Agüero para mantener la composición y fisonomía nacionales en el ejército patrio, e iguales seguridades se pedían para la escuadra. [...] Estas proposiciones, hechas al tiempo mismo en que el presidente consentía en renunciar y expatriarse, acreditan que obedecía a inspiraciones más elevadas que el simple predominio personal (Riva Agüero, 2010, p. 508).

La posición de Riva Agüero a todas luces es de defensa de los intereses del Perú, asumiendo un nacionalismo exacerbado de acuerdo con los fines políticos que tenía en mente, como el poner condiciones para que el 
ejército peruano se integrara al colombiano en la guerra contra las fuerzas realistas, respetando la jerarquía de la oficialidad peruana y la conformación del ejército en cada una de sus partes. De hecho, Riva Agüero no confiaba en la palabra del Libertador y se negó a aceptar sus requerimientos. El presidente estaba dispuesto a renunciar si el Congreso que sostenía a Torre Tagle era disuelto y se convocaba a otro, pero Bolívar sabía que aceptar la propuesta de Riva Agüero incluía dejar sus facultades de dictador y sujetarse a nuevas condiciones políticas que podrían hacerlo salir del país. Al fracasar las negociaciones entre ambas partes, el Congreso establecido en Lima dio autorización al Libertador para emplear la fuerza y apresar al presidente rebelde.

Sin embargo, Riva Agüero ya había iniciado conversaciones con el virrey con el fin de ganar tiempo y evitar la destrucción del ejército que dirigía Santa Cruz, al hallarse en el sur en un estado deplorable, luego de las derrotas de Torata y Moquegua. Así, Riva Agüero contaba con la autorización del Senado establecido en Trujillo e inició las negociaciones con La Serna, teniendo como base la Convención de Buenos Aires del 23 de julio de 1823, por la cual España accedía a firmar tratados con los nuevos Estados y reconocía la independencia. De esta manera, Riva Agüero escribió una carta al virrey con fecha 27 de agosto de 1823, en los siguientes términos:

Ya España ha conocido cuanto le conviene la paz, y aun a costa de la independencia de América ha accedido a la celebración de tratados. Así lo manifiestan los papeles públicos de Europa y los discursos de las Cortes españolas. Desapareció, pues, el obstáculo que impedía a vuestra excelencia entrar en tratados con los independientes, teniendo a la vista el que tenemos el honor de acompañarle entre los comisionados de Su Majestad Católica y los del gobierno de Buenos Aires. [...] Anticipemos los días venturosos que dentro de poco deben venir con la paz; preparemos el camino de esta, anunciando a los pueblos el armisticio; enjuguemos de una vez las lágrimas de una misma familia, que por tan dilatada época ha vivido sumida en la discordia y en los horrores. [...] En la guerra en que estamos empeñados, un día más puede no dejar a España la menor esperanza para sus negocios, los tratados que ahora se hagan asegurarán estos, cuando lleguen sus comisionados, los que habiéndolo ya realizado con el Estado de Buenos Aires, pasan a Chile y Perú con el mismo objeto. [...] Las circunstancias nos autorizan para poner remedio a esta plaga terrible que nos devora; volemos, pues, en auxilio de nuestros hermanos y anunciémosles que ya llegó el día feliz de nuestra reconciliación. A esto está dirigido mi anhelo, y con ello serán cumplidos mis deseos por la felicidad de los pueblos y de esta porción de valientes que tengo el honor de mandar (Rávago, 1999, p. 308). 
Al hacer una lectura entre líneas de esta misiva enviada por Riva Agüero a La Serna, se puede apreciar no solo la visión que tenía el presidente sobre el futuro político del Perú, sino también lo que significaba para él el establecimiento de la nación peruana y su propia identidad como peruano y español. Por una parte, Riva Agüero tenía su particular visión del Perú y propuso al virrey que reconociera la independencia y que se hicieran los preparativos para que un príncipe español viniera al país a fin de establecer una monarquía constitucional en la que peruanos y españoles compartieran sus negocios manteniendo el orden social. Riva Agüero afirmaba que la demagogia practicada por los miembros del Primer Congreso Constituyente había sido la causante de la anarquía y la crisis política. Riva Agüero es, en lo más profundo de su ser, un noble español, pero ha desarrollado un nacionalismo que lo lleva a deponer sus ambiciones políticas para que se establezca un régimen monárquico que garantice la estabilidad política y el progreso del Perú.

El 25 de noviembre de 1823, Riva Agüero fue depuesto como presidente en una rápida intervención militar dirigida por Antonio Gutiérrez de la Fuente, que había sido convencido por Bolívar para que plegarse a su causa. Estando preso en Trujillo, Riva Agüero y los suyos fueron conducidos a Guayaquil por órdenes del Libertador, pero el vicealmirante Guise logró que Bolívar le entregara al prisionero y a su familia, a fin de garantizarles la vida. Ya con protección de los oficiales de la Marina, Riva Agüero salió rumbo al exilio a Europa y no retornó al país hasta muchos años después, cuando ya Bolívar y el ejército colombiano habían dejado el Perú.

\section{Capítulo 2}

\section{Pruvonena y su juicio acerca de los libertadores y políticos del Perú}

Uno de los personajes fundamentales del proceso de independencia fue, sin lugar a dudas, el general rioplatense San Martín, quien llegó al Perú en setiembre de 1820, financiado por el gobierno de Chile, para lograr la libertad del Perú y expulsar a los españoles de esta parte del continente. Riva Agüero lo apoyó incondicionalmente y le ofreció sus servicios en Huaura a poco de haber llegado el Libertador al Perú. Sin embargo, los principales asesores del Protector lo relegaron a un segundo plano y no lo llamaron cuando se discutió el sistema político que convenía al naciente Estado peruano, ni tampoco lo convocaron al crearse la Orden del Sol, siendo Riva Agüero un criollo con ascendiente de nobleza española. Estos hechos hicieron que el futuro primer presidente del Perú tomara distancia de San Martín, a quien en sus memorias trató duramente y lo acusó de ser un gobernante autoritario y saqueador. Así, Riva Agüero expresa que 
Una gran parte del vecindario de Lima, así como muchos conventos, monasterios, capellanías, casa de huérfanos y hospitales, subsistían con los réditos de los capitales impuestos de tiempo inmemorial, sobre la hacienda pública, consulado, cabildo y minería; pero San Martín privó a todos los interesados hasta la esperanza de cobrar sus réditos, por la arbitrariedad con que dispuso de las propiedades de los particulares, así como de las rentas del erario nacional. Durante el tiempo que estuvo en la costa del Perú, sostenido por la escuadra de Chile que mandaba Lord Cochrane, y por las guerrillas peruanas, que en toda esa campaña sostuvieron el honor de las armas de la patria, los comandantes de ellas se apoderaron de grandes sumas en barras de plata y oro. Estos, llevados de su ciego patriotismo, todo lo entregaron a San Martín. [...] Se sabe que las diferentes partidas en barras y en oro componían la suma de muchos centenares de miles de pesos; y también hemos sabido que jamás San Martín hizo uso de ellos en el Perú, sino que casi todo fue robado por él y Monteagudo (Pruvonena, 1858, p. 59).

Riva Agüero, quien utilizó el seudónimo Pruvonena al publicar sus memorias, afirmó que el Protector del Perú en ejercicio de sus funciones tuvo inconductas sociales que lo descalifican como gobernante y lo acusa de tirano y ladrón. Además, expresó que San Martín tuvo como cómplices de sus actos de pillaje a Torre Tagle y a Monteagudo, personajes que no eran de su agrado, por considerarlos demagogos y abusivos contra los hombres de bien, muchos de ellos españoles de buen nombre. Al poner como víctimas a los peninsulares, Riva Agüero dejó en claro su identidad social con quienes consideraba como sus hermanos. Así, Pruvonena manifiesta que

En la ciudad de Trujillo dejó San Martín pidiendo limosna al español D. N. Orbegoso; el que después perdió el juicio, por haberle quitado todos sus bienes que consistían en 30000 pesos en moneda. En la misma ciudad robaron al notario mayor D. N. Merino, hombre extraordinariamente rico, y luego fue fusilado; sin duda, para que en ningún tiempo reclamase. Allí tenía San Martín por agente de estos robos a don José Bernardo Tagle; lo mismo que tenía otros semejantes agentes en las provincias, principalmente en la de Huaylas, que la entregó al general Luzurriaga, su cómplice en los asesinatos de San Luis y Mendoza (Pruvonena, 1858, p. 62).

En otra parte de sus memorias, Pruvonena fustiga la labor del Primer Congreso Constituyente al achacarle la responsabilidad de ocasionar la anarquía y el desgobierno, por nombrar a una primera junta gubernativa compuesta por personas sin méritos para dirigir los destinos del país, incompetentes para el cargo y desconocedores de la realidad peruana, más allá que el interés del Congreso era mandar sobre un Poder Ejecutivo 
débil y con funciones básicas para la administración del aparato estatal. Así, Pruvonena señala que

Separado del Perú el general San Martín, quedó el Primer Congreso Constituyente, ejerciendo en toda su extensión los poderes Legislativo y Ejecutivo. Para administrar el Ejecutivo eligió a tres personas de su seno, bajo la inmediata inspección del Congreso. Estos tres individuos eran diputados suplentes: uno era peruano, otro colombiano y el tercero de la república argentina. Ninguno de ellos había prestado el menor servicio a la causa de la independencia; y antes por el contrario, el uno, el general La Mar, que presidía esa Junta, apenas hacía un año que había capitulado en la plaza del Callao, de la que era gobernador por el gobierno español. ¿Cómo pues con semejantes personas, podía esperarse que prosperase la causa de la independencia? Esta Junta Gubernativa se contrajo exclusivamente a destruir todas las providencias que se habían dictado para asegurar la tranquilidad interior, tanto con respecto a los realistas, como para con los ladrones que infestaban las poblaciones y los caminos (Pruvonena, 1858, p. 114).

Al elaborar un enjuiciamiento de la conducta política de Simón Bolívar en el Perú, Pruvonena revisa el pasado del Libertador y con una rigurosidad digna de un historiador moderno acopia documentos para demostrar que no le impulsó el patriotismo a liderar la lucha contra el yugo español, sino que su actuación fue para encubrir una deuda económica que tenía con la autoridad colonial de Venezuela, la cual no quiso pagar y, por ello, tomó las armas para acabar con el régimen peninsular. De esta manera, Pruvonena menciona que

Daremos aquí principio asentando que Bolívar tomó el partido de la independencia por no pagar a la real hacienda una suma considerable que le debía: este hecho es notorio. El diputado de Venezuela Rafael D. Mérida, en su célebre representación al Congreso de Colombia, lo acusa, en la foja 8 de ella, de que siendo deudor al erario desde antes de la revolución de Venezuela, en una crecida cantidad de miles de pesos, no la quiso jamás satisfacer a la nación, no obstante que estaba cumplido el plazo a que se obligó. He aquí descubierto que no fue por patriotismo al partido que tomó contra la causa del rey, sino por no pagar esa ingente suma a la real hacienda. También se descubre, por esto, que no era Bolívar tan rico como lo han presentado después sus partidarios; porque quien es rico no contrae deudas, y menos se niega a satisfacer sus créditos (Pruvonena, 1858, p. 178).

Al analizar las cartas del mismo Bolívar, Pruvonena se propone descubrir no solo la ambición del Libertador, sino su malsana concepción de liberar al Perú utilizando a su enviado especial, el general Antonio José de 
Sucre, para hacer que los políticos peruanos se peleen unos contra otros y se creara la situación anárquica que los obligara a llamarlo y entregarle el poder absoluto. De este modo se apropiaría de la soberanía y dispondría a su antojo de los recursos económicos de la nación. En este sentido, se puede afirmar que Riva Agüero veía en Bolívar a un seguidor de los postulados políticos de Maquiavelo. En sus memorias publicó un extracto de la carta que el Libertador envió al señor Mosquera, que era su ministro plenipotenciario en Lima, en donde le dice:

Es preciso trabajar, [...] porque no se establezca nada en el país [en el Perú], y el modo mas seguro es dividirlos a todos. La medida adoptada por Sucre, de nombrar a Torre Tagle, embarcando a Riva Agüero con los diputados y ofrecer a este el apoyo de la división de Colombia para que disuelva al Congreso es excelente. Es preciso que no exista ni simulacro de gobierno, y esto se consigue multiplicando el número de mandatarios y poniéndolos a todos en oposición. A mi llegada [a Lima], debe ser el Perú un campo rozado, para que yo pueda hacer en él lo que convenga (Pruvonena, 1858, p. 181).

De otro lado, Pruvonena enjuicia a Luna Pizarro como un demagogo y ambicioso hombre sediento de poder que llevaba el hábito de sacerdote para hacer carrera política antes que por vocación religiosa. En una parte de sus memorias, se aprecia que Pruvonena enfila duramente contra Luna Pizarro por ser un oportunista, pero más aún porque, según él, los sacerdotes debían dedicarse a la vida espiritual y servir a Dios, de acuerdo con su tradicional modo de ver la vocación sacerdotal, y no aprovecharse de su posición eclesiástica para influir en los presidentes y pasar por encima de las leyes. De esta forma, Pruvonena expresa:

el clérigo Luna Pizarro, acreditó bastantemente en su conducta pública, para con aquellas personas que quería hacer desaparecer de la escena política, una alma como la de Chabot, y una ambición más grande que la de Sieyes; pero con mayor orgullo e insolencia tal vez que esos dos sacerdotes apóstatas, a quienes parece haber tomado por modelo en su carrera demagógica. Jamás se ha conocido en el Perú un demagogo más orgulloso: sus odios han sido eternos, siempre vengativo con todo aquel que no se le ha prosternado. Este hombre ha querido siempre mandar en el presidente de la república: lo consiguió en las épocas del presidente La Mar y Orbegoso, y también durante el mando de don Manuel Salazar. La dirección de aquel fue la pérdida de esos gobernantes. Puede decirse que Luna Pizarro, después de Bolívar, es el principal origen de la anarquía que por tanto despedaza al Perú. Luna Pizarro parece haber sido uno de aquellos que toman el estado eclesiástico por carrera y no por vocación (Pruvonena, 1858, p. 294). 
Riva Agüero sabía bien que Luna Pizarro era un liberal que aplicaría los principios políticos y las técnicas que aprendió cuando fue testigo de las intervenciones de los diputados en la corte gaditana. Luna Pizarro había aprendido los mecanismos parlamentarios como la forma de dirigir los debates cuando estuvo presente en la instalación de las Cortes de Cádiz. Fue el grupo liberal, que él encabezó en el Primer Congreso Constituyente, el que propuso que una Junta Gubernativa de tres personas se encargara de las funciones ejecutivas de gobierno, supeditada a las directivas del Congreso a fin de que no tuviera la autonomía y el poder suficiente para hacer oposición al Parlamento como había sucedido con una de las regencias que rompió relaciones con las Cortes de Cádiz. Por esta razón, Riva Agüero consideró a Luna Pizarro como una persona calculadora y peligrosa que quería mantener el poder en manos del Congreso en vez de auspiciar la formación de un Poder Ejecutivo fuerte, como el que Riva Agüero quería dirigir en 1823 al ser impuesto como presidente, que con plenos poderes hiciera frente al ejército español y diera disposiciones en materia económica para recaudar ingresos con los cuales financiar la guerra contra las fuerzas del virrey La Serna.

En sus memorias, Pruvonena descalifica a los políticos peruanos que formaron parte del Primer Congreso Constituyente por ser serviles a Bolívar, ya que les aseguró un empleo y una cuota de poder político que en otras circunstancias nunca habrían tenido. Pruvonena enfatiza la bajeza de los políticos peruanos por venderse al Libertador a cambio de puestos en la administración pública y haber preferido la dominación extranjera a un gobierno dirigido por un peruano como él, que estaba dispuesto inclusive a deponer sus ambiciones políticas para colaborar en el logro de la independencia peruana. De esta manera, Pruvonena menciona:

Es sabido que Bolívar, para ponerse a cubierto de todos sus excesos, y poder asegurarse en la usurpación del Perú, hizo que Sucre y demás agentes suyos instalasen en Lima una farsa a semejanza de Congreso. Esta farsa, titulándose Representación Nacional, no obstante de carecer del requisito esencial de la elección de los pueblos, fue ganada por las dádivas y promesas de Bolívar, y esta le dio en patrimonio el Perú. Si las elecciones populares están expuestas a ser corrompidas, ¿cómo una farsa de gente desconceptuada y ganada de antemano, no había de prostituirse al que los había colocado en esa categoría? Así sucedió, ellos recibieron descaradamente de Bolívar toda clase de colocaciones en los empleos civiles, militares, eclesiásticos, de hacienda y de justicia; y a su vez ellos lo invistieron con la dictadura perpetua y hereditaria (Pruvonena, 1858, p. 289). 


\section{Capítulo 3}

\section{Riva Agüero: sus ideas políticas, económicas y su comprensión de la sociedad peruana}

José de la Riva Agüero y Sánchez Boquete fue un actor beligerante y de actitudes polémicas durante el proceso de la independencia peruana. En sus memorias, Riva Agüero afirma que la desgracia de la anarquía es responsabilidad de los políticos peruanos, quienes siendo miembros del Primer Congreso Constituyente prefirieron ceder su poder político a Bolívar, a cambio de favores y prebendas. En sus memorias, Riva Agüero, que firma como Pruvonena, hace ver en forma clara que la demagogia de los congresistas provocó el desgobierno. Al comparar la situación del Perú con Chile, establece que el estancamiento económico y la falta de control social del Perú nos hace ver inferiores en todo orden de cosas ante el vecino país del sur. Así, Pruvonena expresa:

Chile sin haber tenido, después que sacudió el yugo de España, dominadores extranjeros, ha dispuesto y arreglado sus negocios conforme al verdadero interés público. Por la misma razón, Chile no ha sucumbido por mucho tiempo a los manejos de la demagogia, porque allí se reunieron los propietarios e hicieron resistencia a los ideólogos que los conducían, con sus teorías y faltas de moral, al abismo en que se halla el Perú. Así Chile ha ganado tanto en la independencia cuanto ha perdido el Perú; esto es, aquel país ha llegado a ser independiente y ha arreglado por sí mismo su administración; mientras el Perú no ha salido todavía de la tutela de Chile, Buenos Aires, Colombia, Bolivia, y de un enjambre de anarquistas. Por esta razón no hay persona alguna en Chile que no esté contenta con haberse sacudido de la dependencia de España, mientras que en el Perú, excepto los anarquistas, todo el mundo reniega de la miseria y desorden que ha introducido esa anarquía, que apellidan libertad e independencia (Pruvonena, 1858, p. 284).

En cierta forma, se aprecia que Riva Agüero tiene una concepción política autoritaria, puesto que solo un gobierno fuerte puede evitar la anarquía que en el Perú fue sembrada por los congresistas y su demagogia, que prefirieron entregar el país a la tutela colombiana de Bolívar antes que propiciar la unión de todos los peruanos para enfrentar el peligro que representaba el ejército español. Riva Agüero sabe que Chile está en mejor situación que el Perú, porque ahí los empresarios y los propietarios no se dejaron amilanar por los generales de tropa ni por los políticos, sino que hicieron prevalecer sus derechos como ciudadanos. Es cierto que Chile se independiza más del Perú que de España, pero aun así procura afirmar su dominio político y económico en la región para expandirse hacia el 
norte a costa del débil Estado peruano. Por ello, invadirá el Perú unos años después para deshacer la Confederación Perú-Boliviana.

Riva Agüero era partidario de establecer la monarquía constitucional en el Perú, porque la mayoría de la población peruana era iletrada. No se podían dar amplios derechos políticos a los habitantes del país, ya que no todos los hombres eran iguales, y había muchos que no tenían la capacidad necesaria para gobernar y decidir el futuro del país. Así, Riva Agüero creía que el gobierno debía estar en manos de los ilustrados y se mostraba opuesto a la democracia, porque era un sistema que promovía el libertinaje y ello iría en contra del mantenimiento del orden social en el Perú. Al respecto, en sus memorias Pruvonena manifiesta:

Las instituciones puramente democráticas son pues inadaptables para el Perú; porque careciendo sus habitantes de las luces, educación y costumbres que requiere este sistema de gobierno, y además, componiéndose la mayor parte de su población de indios, mestizos y negros, falta lo más esencial, que es la homogeneidad en la nación. No habiendo esta homogeneidad, es todavía más imposible establecer esa absoluta igualdad entre semejantes gentes; y así es que por resultado no se ha conseguido otra cosa que la anarquía. Sabiamente ha dicho Voltaire: "Los que dicen que todos los hombres son iguales, dicen la más grande verdad, si comprenden que todos los hombres tienen un derecho igual a la libertad, a la propiedad de sus bienes y la protección de las leyes; pero se engañan mucho si creen que los hombres deben ser iguales para los empleos, supuesto que no lo son absolutamente en sus talentos» (Pruvonena, 1858, p. 291).

Riva Agüero achaca la responsabilidad de la anarquía a los liberales, que con sus ideas copiadas de los ideólogos que realizaron la revolución de 1789 en Francia, sembraron el caos político y social en los primeros años de vida republicana del Perú; además, les crítica duramente el hecho de utilizar su poder político para subir de nivel social y el de sus coterráneos, dando el título de ciudades a pequeños pueblos habitados por gente sin ilustración ni cultura, por lo que iban en contra del orden natural que siguen las sociedades civilizadas. La alteración del orden social a través de las maniobras políticas era condenada por Riva Agüero, quien durante su ejercicio como presidente luchó por mantener el orden interno y el control social de la población para evitar desmanes y revueltas. Así, Pruvonena señala:

Los demagogos peruanos han querido llevar la teoría de la igualdad más allá todavía, que sus maestros los jacobinos de la Revolución francesa; estos quisieron igualar la clase proletaria de la sociedad a la de los hombres ilustrados y de una educación esmerada, y aquellos 
no solamente han seguido este absurdo en cuanto a nivelar todas las clases y condiciones de los habitantes del Perú, sino que extendieron estas falsas ideas hasta el extremo de decretar que los pueblos más reducidos se llamasen ciudades. Creían que ellos se daban más importancia, dándoles a los pueblos de su nacimiento el pomposo título de ciudad. Pueblos compuestos de unas cuantas casas medianas han sido elevadas a ciudades, como si los decretos o leyes que les dan esta denominación pudiesen ser bastantes para transformar la naturaleza, y convertir las chozas en casas, y los medio-salvajes en ciudadanos (Pruvonena, 1858, p. 292).

Asimismo, Riva Agüero hace recuerdo en sus memorias del pésimo manejo económico del Congreso que lo destituyó de la Presidencia en 1823, al afirmar que los parlamentarios eran responsables de la crisis económica del Estado peruano por no incentivar la producción y por incumplir con el pago de la deuda, a través de una maniobra legal, que se tenía con los propietarios peruanos que habían dado sus bienes para financiar al ejército patriota durante la guerra de independencia. Es claro que Riva Agüero en materia económica piensa que la riqueza del Perú es producida por la clase propietaria, y si el Estado, en vez de apoyarla, deja de pagarles los capitales que se le deben, esto traerá como consecuencia la paralización de la actividad comercial, la crisis de la industria y el empobrecimiento de los trabajadores. De esta manera, Pruvonena expresa:

El Congreso del Perú dio un golpe mortal a la propiedad con la ley de bancarrota del Estado; casi a la manera que se hizo en Francia con los asignados, o deuda nacional. A esto equivale la ley dada, para que cesen de satisfacerse los intereses de la deuda nacional interna, y que no corran para lo sucesivo esos intereses o réditos, así como también que no se paguen ni amorticen los capitales de ella, hasta que se pague la deuda contraída por el tiempo de la independencia. Esto es casi una bancarrota fraudulenta, porque aumentándose cada día más la deuda moderna, es ya en la actualidad más que triple que la del tiempo anterior a la independencia. [...] Los demagogos del figurado Congreso supletorio se mostraron desde el principio celosos sectarios, como hemos dicho, de los jacobinos de Francia. Como ellos, perdieron a cuantas personas no las consideraban bastante depravadas, o débiles para hacer con ellos común, persiguieron a todo patriota verdadero y adicto al orden: destruyeron a los propietarios, reduciendo sus propiedades a la sexta u octava parte de su valor, por medio de la autorización de la usura en el interés del dinero (Pruvonena, 1858, p. 294).

Por otro lado, Riva Agüero deja en claro su particular visión sobre las uniones matrimoniales al afirmar que un zambo no puede por casarse con una mujer blanca y noble, porque es ir contra el orden natural de las cosas 
establecido por la sociedad. El quebrar ese principio básico del orden social sería indecente y digno de la gente vulgar. Riva Agüero afirma que los negros no son virtuosos, por más revolucionarios que sean, son falsos y no pueden unirse a los nobles. Así, Pruvonena pone el caso de Simón Bolívar, a quien considera un arribista, y manifiesta:

Ciertamente es cosa bien notable que Bolívar, salido de la oscuridad a la sombra de la democracia, por la que se veía en un rango tan elevado, se hubiese infatuado tanto, que se olvidase de sus humildes principios, y se creyese ya, digno de ocupar un trono, y de obtener una princesa real por mujer. Todos los que conocen a Bolívar y a su familia, excepto sus compañeros en esa farsa, saben que él, no podía ser bueno para lacayo de un monarca de Europa; porque su color no era la de los lacayos europeos. Nos bastará decir aquí que el general colombiano Silva, su sobrino político, es un zambo casi enteramente negro, y que a ese hombre soez lo casó Bolívar con una sobrina suya. Véase, pues, que los que tanto han querido hacer aparecer a Bolívar como hombre de familia decente lo han hecho solamente por el interés que tenían en propagar esa falsedad. ¡Qué tal enlace con una princesa de la casa de Borbón! (Pruvonena, 1858, p. 219).

\section{Conclusiones}

1. Riva Agüero tiene su propia visión del Perú. Cree firmemente que los ilustrados deben dirigir los destinos de la nación y la monarquía constitucional es el mejor sistema político para mantener el orden político y social del país. Su objetivo es libertar al Perú y, para ello, asume una conducta nacionalista, por la cual defiende la jerarquía de los oficiales peruanos que estaban al mando del ejército patriota frente a los colombianos.

2. Riva Agüero afirma que los culpables de la anarquía del Perú, luego de la salida del libertador San Martín, son los miembros del Primer Congreso Constituyente, a quienes califica de demagogos y traidores, por permitir que Bolívar asumiera poderes absolutos antes que apoyar a un peruano como él para hacer frente a las tropas del virrey La Serna.

3. En sus memorias, Riva Agüero, utiliza el seudónimo de Pruvonena y tilda a los libertadores San Martín y Bolívar de ser estafadores y despóticos. A Bolívar lo descalifica por ser un hombre deshonesto y ambicioso cuyo objetivo no era libertar al Perú, sino crear la anarquía para obligar a los políticos peruanos que lo declararan dictador.

4. Las ideas políticas y sociales de Riva Agüero son las de mantener el orden social como base para ejecutar un buen gobierno, el cual debe estar dirigido por los ciudadanos ilustrados que hagan posible el progreso del Perú. 


\section{Contribución del autor}

Juan Alberto San Martín Vásquez ha participado en la concepción, la recolección de datos, la redacción y la aprobación de la versión final del artículo.

\section{Fuente de financiamiento}

Autofinanciado.

\section{Conflictos de interés}

El autor declara no tener conflictos de interés. 


\section{REFERENCIAS BIBLIOGRÁFICAS}

\section{A. Fuentes de información}

Mariátegui, F. (1925). Anotaciones a la Historia del Perú Independiente de don Mariano Felipe Paz Soldán. En Dos controversias históricas. Lima: Editorial Garcilaso, pp. 5-135.

Pruvonena (1858). Memorias y documentos para la historia de la Independencia del Perú y causas del mal éxito que ha tenido esta. París: Librería de Garnier Hermanos.

\section{B. Bibliografía}

Hernández García, E. (2019). José de la Riva Agüero y Sánchez Boquete (1783-1858). Primer presidente del Perú. Lima: Fondo Editorial del Congreso del Perú.

Rávago Bustamante, E. de (1999). El Gran Mariscal Riva Agüero, primer Presidente y prócer de la peruanidad. Lima: edición privada.

Riva-Agüero, J. de la (2010). La historia en el Perú (tesis de doctorado en Letras). Lima: Pontificia Universidad Católica del Perú e Instituto RivaAgüero.

Riva-Agüero, J. de la (1971). El mariscal don José Mariano de la Riva Agüero. En Obras completas de José de la Riva-Agüero. Estudios de historia peruana: La Emancipación y la República. Tomo VII (pp. 161-170). Lima: Pontificia Universidad Católica del Perú.

Rivara de Tuesta, M. (1972). Ideólogos de la Emancipación peruana. Lima: Comisión Nacional del Sesquicentenario de la Independencia del Perú.

San Martín Vásquez, J. (2015). El diputado Ramón Olaguer Feliú y su actuación en las Cortes de Cádiz. Tiempos. Revista de Historia y Cultura, 10, pp. 69-75.

Villanueva, C. (2016). Francisco Javier de Luna Pizarro. Parlamentario y primer presidente del Congreso peruano. Lima: Fondo Editorial del Congreso del Perú, Pontificia Universidad Católica del Perú e Instituto Riva-Agüero. 